\title{
Prevalence of secondary medical complications and risk factors for pressure ulcers after traumatic spinal cord injury during acute care in South Africa
}

\author{
C Joseph and L Nilsson Wikmar
}

Study Design: Prospective, population-based cohort study.

Objectives: To determine the prevalence of selected complications following traumatic spinal cord injury during acute care and to identify the risk factors for pressure ulcers.

Setting: The only tertiary academic (Groote Schuur) hospital in the catchment region providing specialised acute care.

Methods: A descriptive, observational study of an inception cohort. Secondary complications were predefined and consisted of pressure ulcers, pulmonary complications (pneumonia and atelectasis), urinary tract infections, autonomic dysreflexia, deep vein thrombosis, pulmonary embolism, postural hypotension, neuropathic pain and spasticity. Possible risk factors for pressure ulcers included variables concerning demographic and injury characteristics and complications. Both univariate and multivariate logistic regression analyses were used.

Results: Data of 141 patients (97\%) were analysed. In total, 71 (50.3\%) patients had one or more complication. The most common was pressure ulcers $(n=42 ; 29.8 \%)$, followed by pulmonary complications $(n=33 ; 23.4 \%)$ and urinary tract infections $(n=24 ; 17 \%)$. Significant risk factors were gun-shot injury, motor completeness (American Spinal Injury Association Impairment Scale (AIS) A|B), vertebral injury, no spinal surgery, pulmonary complications, urinary tract infection and level of consciousness. In the final multivariate model that correctly predicted $81.6 \%$ of subjects, motor completeness and vertebral injury remained significant independent factors, whereas having a urinary tract infection was associated with an increased risk (odds ratio: 2.86), but not significant at the $5 \%$ level. Conclusion: Pressure ulcers and pulmonary complications were prevalent during specialised acute phase. The occurrence of pressure ulcers, despite protocols in place, is worrisome. To prevent pressure ulcers, special attention seems necessary for persons with motor complete lesions and those with vertebral injuries.

Spinal Cord (2016) 54, 535-539; doi:10.1038/sc.2015.189; published online 20 October 2015

\section{INTRODUCTION}

For patients with traumatic spinal cord injury (tSCI), life expectancy increased substantially over the last few decades owing to medical advances that led to the provision of comprehensive care that is organised in a systematic manner. ${ }^{1}$ The physiological changes in the aftermath of an acute spinal cord injury (SCI) require the prevention of complications that might reduce the chances of survival and recovery. ${ }^{2,3}$ To date, evidence-based (acute) clinical practice guidelines for the management of SCI have been made available to improve care and outcomes. ${ }^{4}$

The SCI care in the South African healthcare context is under development, and, to date, a specialised acute SCI unit has been established. Owing to the need of a higher patient turnover at the hospital, imposed by the high incidence of tSCI in the local context, ${ }^{5}$ it is important to reduce complications during this phase of care. Only one previous study assessed secondary complications in the South African healthcare, reporting solely on the prevalence of pressure ulcers (PUs) in persons with cervical lesions. ${ }^{6}$ This study, conducted in the local context, found a high prevalence of PUs among acute survivors of cervical lesions. ${ }^{6}$ In response, an intervention study was carried out that included the use of pressure-relief mattresses, the administration of the Waterlow Risk Assessment Scale on admission and the appointment of a turning team to assist with regular pressure relief. ${ }^{7}$ Despite the implementation of these strategies, PUs were still not eradicated. Studies in the United States and Europe identified risk factors for PUs in SCI; ${ }^{8-11}$ however, the identification of risk factors for the local context is lacking.

Beside PUs, persons with SCI are known to be vulnerable to develop many other secondary medical complications such as atelectasis, pneumonia and urinary tract infections (UTIs). Studies from the United States ${ }^{12}$ and Europe ${ }^{2}$ commonly report these complications as the most frequent during acute care. These secondary complications have been associated with poorer survival and health outcomes, and a longer duration of hospital stay. ${ }^{2,3}$ However, the prevalence of these secondary complications in South African healthcare is unknown. This knowledge gap hinders the allocation of resources necessary for addressing complications that negatively impact the individual. 
Therefore, the aims of this prospective, population-based study were: (i) to describe the prevalence of selected secondary complications, including PUs, pulmonary complications (pneumonia and atelectasis), UTIs, autonomic dysreflexia, deep vein thrombosis, pulmonary embolism, postural hypotension, neuropathic pain and spasticity, and (ii) to identify the risk factors for PU development during the specialised acute care phase.

\section{MATERIALS AND METHODS}

\section{Design and participants}

This was a descriptive, observational study of an inception cohort that was identified in a regional, population-based cohort study that investigated the incidence and aetiology of tSCI in the City of Cape Town, South Africa. ${ }^{5}$ Inclusion of participants was based on the following criteria: those with confirmed acute tSCI or cauda equina lesion; age $\geqslant 18$ years at the time of injury; admittance to one of the government-funded hospitals between 15 September 2013 and 14 September 2014; survival of at least 7 days post trauma; and those permanently residing in the catchment region. Further, participants who were intermediately managed at another hospital, which in all cases provided general care, whilst awaiting placement at the specialised hospital were only screened for new complications during their acute care stay and not for existing complication(s). Exclusions were those with an ASIA Impairment scale E after 7 days post injury.

\section{Setting}

Specialised acute care, within the catchment of the Cape Metropolitan (Greater Cape Town) area of South Africa, is only provided at Groote Schuur Hospital, which is a tertiary-level healthcare facility. Specialised care in the local context starts, as recommended, ${ }^{4}$ on admission to the level I trauma unit; thereafter, patients are referred to either the acute SCI, neurosurgery or orthopaedic intensive care units. Acute care ended once participants were referred to a different level of care (either rehabilitation or palliative care (including home)). At the hospital, SCI care is provided by one consultant and two specialists in neurology. The specialists managed all the patients with SCI, including those in the neurosurgery, orthopaedic and medical intensive care units.

\section{Data collection tools}

The International SCI Core Data Set was used to collect information concerning demographic and event characteristics and neurological classification. ${ }^{13}$ The neurological assessment, performed by the attending neurologists, was carried out in accordance with international standards. ${ }^{14}$ The list of variables was extended by including secondary medical complications, which included the following: PUs, pulmonary disease/infection (atelectasis and pneumonia), UTIs, deep vein thrombosis, autonomic dysreflexia, pulmonary embolism, postural hypotension, spasticity, neuropathic/spinal cord pain and other. The selected medical complications were screened weekly by the medical team for the duration of specialised acute hospitalisation. To improve centralisation of secondary medical complication information, a standardised list was created with response options for the presence of respective complication, degree or severity and mode of diagnosis. The neurologists and a specialised nurse were responsible for registering each complication on a standardised list after ward meetings. The presence of complications was based on the operational definition followed by the hospital (Supplementary Appendix 1).

\section{Data analyses}

Demographic and injury characteristics and the prevalence of medical complications were analysed descriptively. Possible risk factors for stage II to IV PUs were assessed using logistic regression analyses. Some factors were recoded into dummy variables. For example, age was divided into four categories, namely $18-30,31-45,46-60$ and $\geqslant 61$. Also, the American Spinal Injury Association Impairment Scale (AIS) classification was dichotomised into motor complete (AIS A $\mid$ B) and incomplete (AIS C|D) lesions. ${ }^{11}$ This dichotomisation was carried out because no data were available on the functioning levels and mobility of participants. In the end, motor completeness of lesions was used as a proxy for function/mobility. Initially, all potential risk factors were entered one at a time in unadjusted univariate logistic regression models. At this point, significant predictors were set at alpha level equal to 0.10 for further inclusion in the multivariable analyses. Prior to multivariable analyses, correlation analyses were computed to assess collinearity among potential risk factors. Lastly, predictors were entered into a multivariable logistic regression model where confounders were added if causing a change in $B$ (unstandardised regression coefficient) of the independent variables that exceeded $10 \%$. The statistical significance level was set at $P \leqslant 0.05$ (STATA Corp, College Station, TX, USA). The predicted model was found to fit if the Hosmer and Lemeshow test (for goodness of fit) was non-significant, $P>0.05$, and to have acceptable discrimination if the area under the receiver operating characteristic curve was $>0.7$.

\section{Ethics}

We certify that all applicable institutional and governmental regulations concerning the ethical use of human volunteers were followed during the course of this research. In particular, ethical permission was granted by the University of the Western Cape's Senate Research Committee (registration number: 13/4/27), and permission to conduct the study at the specialised hospital was provided by the Chief Executive Officer. All participants in this study provided written informed consent.

\section{RESULTS}

\section{Participants' injury characteristics}

One hundred and forty-five newly injured persons with tSCI were included in the study, of which the data of 141 were analysed. The main cause of injury was assault, accounting for $59.3 \%$ of spinal cord lesions in the cohort, followed by transport-related events (Table 1). Concerning associated injuries in this cohort, the most common was internal organ damage combined with hemorrhage $(n=38)$, followed by major chest injuries $(n=29)$. Of the cohort, 33 patients were intermediately managed at other hospitals, and the median time to be admitted to the specialised hospital was 12 days, ranging between 2 and 53 days. The mean and median length of specialised acute care were 36.5 (s.d.: 36.8) and 24 (range: 3-245) days, respectively.

\section{Prevalence of selected secondary medical complications}

As shown in Table 2, a total of $71(50.3 \%)$ patients had one or more secondary complication. The most common was PUs $(n=42 ; 29.8 \%)$, followed by pulmonary complications $(n=33 ; 23.4 \%)$ and UTIs $(n=24 ; 17 \%)$. Of the total sample, $25.5 \%$ presented with one complication, $16.6 \%$ with two and $8.3 \%$ with three or four. By neurological level, the mean number of complications per patient was $1.0,0.8$ and 0.3 for those with cervical, thoracic and lumbar lesions, respectively (Table 3 ).

\section{Risk factor analyses of PUs}

Univariate logistic regression results (Table 4) revealed that those sustaining their injuries due to gun-shot injuries were 3.5 times (odds ratio $(\mathrm{OR})=4.5 ; 95 \%$ confidence interval $(\mathrm{CI}): 2.07-9.76)$ more likely to develop PUs, compared with all other types of etiologies. Those with complete motor lesions and vertebral injuries were seven $(\mathrm{OR}=$ 8.13; 95\% CI: 3.39-19.49) and close to four (OR $=4.97$; 95\% CI: 1.64-15.09) times more likely for PU development, respectively, compared with those without such additions. Further, the development of pulmonary complications and UTI were associated with risks of $4(\mathrm{OR}=5.02$; 95\% CI: $2.19-11.59)$ and 3.5 times $(\mathrm{OR}=4.45 ; 95 \%$ CI: 1.78-11.12) of PU, respectively. In our data, we observed that those with moderately and severely altered consciousness had higher risks of developing PUs, compared with those with normal or mildly affected consciousness. Although not statistically significant, protective 
Table 1 Participants' injury characteristics

\begin{tabular}{|c|c|c|}
\hline \multicolumn{3}{|l|}{ Characteristics } \\
\hline Total $(N, \%)$ & 145 & 100 \\
\hline \multicolumn{3}{|l|}{ Gender (n, \%) } \\
\hline Male & 124 & 85.5 \\
\hline Female & 21 & 14.5 \\
\hline Age at injury (mean and s.d.) & 33.5 & 13.8 \\
\hline Age at injury (median and range) & 29 & $18-93$ \\
\hline $18-30(n, \%)$ & 78 & 54 \\
\hline $31-45$ & 41 & 28 \\
\hline $45-60$ & 18 & 12 \\
\hline$\geqslant 61$ & 8 & 6 \\
\hline \multicolumn{3}{|l|}{ Aetiology (n, \%) } \\
\hline Sport & 1 & 0.7 \\
\hline Assault & 86 & 59.3 \\
\hline Transport & 38 & 26.2 \\
\hline Falls & 17 & 11.7 \\
\hline Other traumatic cause & 3 & 2.1 \\
\hline \multicolumn{3}{|l|}{ Neurological category } \\
\hline Ventilation dependent & 0 & 0 \\
\hline C1-C4 AIS A (complete; $n, \%$ ) & 13 & 34.2 \\
\hline C1-C4 AIS B, C, D (incomplete; $n, \%$ ) & 25 & 65.8 \\
\hline C5-C8 AIS A (complete; $n, \%$ ) & 10 & 25.6 \\
\hline C5-C8 AIS B, C, D (incomplete; n, \%) & 29 & 74.4 \\
\hline T1-S5 AIS A (complete; n, \%) & 34 & 50 \\
\hline T1-S5 AIS B, C, D (incomplete; n, \%) & 34 & 50 \\
\hline \multicolumn{3}{|l|}{ Associated injuries ${ }^{\mathrm{a}}$ (n, \%) } \\
\hline Yes & 84 & 57.9 \\
\hline No & 61 & 42.1 \\
\hline \multicolumn{3}{|l|}{ Vertebral injury (n, \%) } \\
\hline Yes & 106 & 73.1 \\
\hline No & 39 & 26.9 \\
\hline \multicolumn{3}{|l|}{ Spinal surgery (n, \%) } \\
\hline Yes & 75 & 51.7 \\
\hline No & 70 & 48.3 \\
\hline Time to spinal surgery ${ }^{b}$ (Mean and s.d.) & 9.93 & 9.5 \\
\hline Time to spinal surgery (median and range) & 7 & $0-45$ \\
\hline
\end{tabular}

Abbreviation: AIS, American Spinal Injury Association Impairment Scale.

associated injuries included moderate to severe traumatic brain injury, non-vertebral fractures requiring surgery, severe facial injuries, major chest injury requiring mechanical ventilation and severe hemorrhaging, or damage to internal organs.

bTime to spinal surgery $=$ reflects the time since the onset of the injury.

effects were found for those with $\geqslant 12$ years of education $(\mathrm{OR}=0.77)$ compared with those with no schooling or $<12$ years of education, those who underwent spinal surgery $(\mathrm{OR}=0.52)$, and those of mixedrace and White origin.

The multivariable logistic regression model revealed that complete motor injuries (AIS A $\mid \mathrm{B})(\mathrm{OR}=3.51 ; 95 \% \mathrm{CI}: 1.22-10.04)$ and vertebral injuries $(\mathrm{OR}=4.40 ; 95 \% \mathrm{CI}: 1.10-17.58)$ were the major independent risk factors for PU development. Although not significant at the $5 \%$ level, those with UTIs were, independently, $1.86(\mathrm{OR}=2.86$; 95\% CI: 0.90-9.09) times more likely to develop PUs $(P=0.075)$ in the model controlled for potential confounders. In this model, on the basis of the Hosmer and Lemeshow goodness of fit test $(P=0.83)$, the predicted probabilities were not significantly different from the
Table 2 Nature and prevalence of secondary medical complications

\begin{tabular}{lc}
\hline Complications & $\mathrm{n}(\%)$ \\
\hline Pressure ulcers & $42(29.8)$ \\
Pulmonary complications (pneumonia and atelectasis) & $33(23.4)$ \\
Urinary tract infection & $24(17.0)$ \\
Autonomic dysreflexia & $2(1.4)$ \\
Deep vein thrombosis & $8(5.7)$ \\
Pulmonary embolism & $1(0.7)$ \\
Postural hypotension & $2(1.4)$ \\
Neuropathic pain & $8(5.7)$ \\
Spasticity & $4(2.8)$ \\
Total patients with $\geqslant 1$ complication & $71(50.3)$ \\
Patients with 1 complication & $36(25.5)$ \\
Patients with 2 complications & $23(16.6)$ \\
Patients with $\geqslant 3$ complications & $12(8.3)$ \\
\hline
\end{tabular}

$N=141$ data sets were included in the analyses.

Table 3 Complications and neurological level

\begin{tabular}{lcccc}
\hline Complications & $\begin{array}{c}\text { Cervical } \\
(\mathrm{n}=74) ;\end{array}$ & $\begin{array}{c}\text { Thoracic } \\
(\mathrm{n}=54) ;\end{array}$ & $\begin{array}{c}\text { Lumbar } \\
(\mathrm{n}=13) ;\end{array}$ & $\begin{array}{c}\text { Total } \\
\mathrm{N}=141) ; \\
\end{array}$ \\
$\mathrm{n}(\%)$ & $\mathrm{n}(\%)$ & $\mathrm{n}(\%)$ & $\mathrm{N}(\%)$ \\
\hline Pulmonary & $23(31)$ & $9(17)$ & $1(8)$ & $33(23.4)$ \\
complications & & & & \\
Pressure ulcers & $23(31)$ & $18(33)$ & $1(8)$ & $42(29.8)$ \\
Urinary tract infection & $15(20)$ & $9(17)$ & & $24(17)$ \\
Autonomic dysreflexia & $2(3)$ & & & $2(1.4)$ \\
Deep vein thrombosis & $1(1)$ & $5(9)$ & $2(15)$ & $8(5.7)$ \\
Pulmonary embolism & $1(1)$ & & & $2(1.4)$ \\
Postural hypotension & $1(1)$ & $1(2)$ & & $8(5.7)$ \\
Neuropathic pain & $5(7)$ & $3(6)$ & & $4(2.8)$ \\
Spasticity & $4(5)$ & & & \\
Mean per patient & 1.0 & 0.8 & 0.3 & \\
\hline
\end{tabular}

$N=141 ;$ four missing cases.

observed probabilities. The accuracy diagnostics of the model revealed that $81.6 \%$ of the outcome was correctly classified (Table 5 ).

\section{DISCUSSION}

The results of this prospective, population-based cohort study indicated that some of the selected secondary medical complications were common during acute care, with more than $50 \%$ of the cohort developing at least one complication. PUs were commonest despite protocols to reduce and eradicate its occurrence, followed by pulmonary complications and UTIs. As PUs were the predominant complication, risk factors were examined where motor complete injuries and vertebral injuries remained independently associated.

Concerning the prevalence of medical complication in our study, similar results in a recent Dutch study found PUs (32\%) and pulmonary complications $(28 \%)$ to be the leading complications during the acute phase. ${ }^{2}$ In the United States, $20-30 \%$ of individuals develop at least one PU within the first 5 years after injury, and it was further found to be one of the chief reasons for re-hospitalisation following acute SCI. ${ }^{15}$ Differentially, the prevalence of PUs, pulmonary complications and UTIs in our study was much higher than reported 
Table 4 Univariate logistic regression analysis of pressure ulcers

\begin{tabular}{|c|c|c|}
\hline Variables & OR $(95 \% \mathrm{Cl})$ & P-value \\
\hline $\begin{array}{l}\text { Gender } \\
\text { Male } \\
\text { Female }\end{array}$ & $\begin{array}{l}2.88(0.80-10.40) \\
1.00 \text { (reference) }\end{array}$ & 0.10 \\
\hline $\begin{array}{l}\text { Age } \\
\quad 18-30 \\
31-45 \\
46-60 \\
\geqslant 61\end{array}$ & $\begin{array}{l}1.00 \text { (reference) } \\
1.25(0.56-2.80) \\
0.14(0.02-1.23) \\
0.72(0.13-3.89)\end{array}$ & $\begin{array}{l}0.58 \\
0.04 \\
0.70\end{array}$ \\
\hline $\begin{array}{l}\text { Aetiology } \\
\text { Sport and work-related } \\
\text { Assault } \\
\text { Transport } \\
\text { Falls }\end{array}$ & $\begin{array}{l}0.61(0.06-6.23) \\
1.00 \text { (reference) } \\
0.34(0.13-0.94) \\
1.02(0.31-3.34)\end{array}$ & $\begin{array}{l}0.67 \\
0.03 \\
0.98\end{array}$ \\
\hline $\begin{array}{l}\text { Gun-shot injury } \\
\text { Yes } \\
\text { No }\end{array}$ & $\begin{array}{l}4.50 \text { (2.07-9.76) } \\
1.00 \text { (reference) }\end{array}$ & $<0.00$ \\
\hline $\begin{array}{l}\text { Sub-classification of injury } \\
\text { Tetraplegia } \\
\text { Paraplegia }\end{array}$ & $\begin{array}{l}1.09 \text { (0.53-2.26) } \\
1.00 \text { (reference) }\end{array}$ & 0.81 \\
\hline $\begin{array}{l}\text { Completeness of injury } \\
\text { Complete } \\
\text { Incomplete }\end{array}$ & $\begin{array}{l}8.13 \text { (3.39-19.49) } \\
1.00 \text { (reference) }\end{array}$ & $<0.00$ \\
\hline $\begin{array}{l}\text { Vertebral injury } \\
\text { Yes } \\
\text { No }\end{array}$ & $\begin{array}{l}4.97(1.64-15.09) \\
1.00 \text { (reference) }\end{array}$ & 0.00 \\
\hline $\begin{array}{l}\text { Associated injury } \\
\text { Yes } \\
\text { No }\end{array}$ & $\begin{array}{l}1.44 \text { (0.68-3.03) } \\
1.00 \text { (reference) }\end{array}$ & 0.34 \\
\hline $\begin{array}{l}\text { Pulmonary complication } \\
\text { Yes } \\
\text { No }\end{array}$ & $\begin{array}{l}5.02(2.19-11.59) \\
1.00 \text { (reference) }\end{array}$ & $<0.00$ \\
\hline $\begin{array}{l}\text { UTI } \\
\text { Yes } \\
\text { No }\end{array}$ & $\begin{array}{l}4.45(1.78-11.12) \\
1.00 \text { (reference) }\end{array}$ & 0.00 \\
\hline $\begin{array}{l}\text { Neuropathic pain } \\
\text { Yes } \\
\text { No }\end{array}$ & $\begin{array}{l}4.32 \text { (0.98-19.01) } \\
1.00 \text { (reference) }\end{array}$ & 0.053 \\
\hline $\begin{array}{l}\text { Spine surgery } \\
\text { Yes } \\
\text { No }\end{array}$ & $\begin{array}{l}0.52 \text { (0.25-1.09) } \\
1.00 \text { (reference) }\end{array}$ & 0.08 \\
\hline $\begin{array}{l}\text { Level of consciousness } \\
\quad \text { Normal/mild } \\
\text { Moderate } \\
\text { Severe }\end{array}$ & $\begin{array}{l}1.00 \text { (reference) } \\
6.07(1.36-27.04) \\
3.64(1.01-13.14)\end{array}$ & $\begin{array}{l}0.007 \\
0.03\end{array}$ \\
\hline $\begin{array}{l}\text { Education } \\
\quad<12 \text { years } \\
\quad \geqslant 12 \text { years (including tertiary) }\end{array}$ & $\begin{array}{l}1.00 \text { (reference) } \\
0.77(0.32-1.81)\end{array}$ & 0.54 \\
\hline $\begin{array}{l}\text { Pre-injury employment } \\
\text { No } \\
\text { Yes }\end{array}$ & $\begin{array}{l}1.00 \text { (reference) } \\
1.16(0.56-2.42)\end{array}$ & 0.21 \\
\hline $\begin{array}{l}\text { Ethnicity } \\
\text { African } \\
\text { Mixed-race/White }\end{array}$ & $\begin{array}{l}1.38 \text { (0.67-2.88) } \\
1.00 \text { (reference) }\end{array}$ & 0.38 \\
\hline
\end{tabular}

Abbreviations: AIS, American Spinal Injury Association Impairment Scale; $\mathrm{Cl}$, confidence interval; OR, odds ratio; UTI, urinary tract infection. We dichotomised completeness on the basis of motor function; thus, motor complete by combining ASIA A and B (ASIA A|B) and motor incomplete by aggregating ASIA C and D (ASIA C |D)

${ }^{a}$ Completeness of injury was determined using the ASIA classification.

Bold values indicate significant association with PUs at the $5 \%$ level.

in a study conducted in China. ${ }^{7}$ These differences could be attributed to the retrospective design used in the latter study, which tends to underestimate the outcome.
Table 5 Multivariable logistic regression model for pressure ulcer

\begin{tabular}{|c|c|c|c|}
\hline Variables & OR $(95 \% \mathrm{Cl})$ & $\mathrm{P}$-value & $\begin{array}{c}\text { Percentage } \\
\text { correct predicted }\end{array}$ \\
\hline Motor complete injury & & & 81.6 \\
\hline Complete (AIS A|B) & $3.51(1.22-10.04)$ & 0.019 & \\
\hline Incomplete (AIS C |D) & 1.00 (reference) & & \\
\hline \multicolumn{4}{|l|}{ Vertebral injury } \\
\hline Yes & $4.40(1.10-17.58)$ & 0.036 & \\
\hline No & 1.00 (reference) & & \\
\hline \multicolumn{4}{|l|}{ UTI } \\
\hline Yes & 2.86 (0.90-9.09) & 0.075 & \\
\hline No & 1.00 (reference) & & \\
\hline
\end{tabular}

Abbreviations: AIS, American Spinal Injury Association Impairment Scale; $\mathrm{Cl}$, confidence interval; $\mathrm{OR}$, odds ratio; UTI, urinary tract infection. All significant $(P \leqslant 0.10)$ covariates on univariate analyses were included. At the end, the fitted model was adjusted for gender, gunshot etiology, presence of associated injury, level of consciousness and whether spinal surgery was performed, development of pulmonary complications and neuropathic pain. surgery was performed, development of pulmonary complications and
Bold values indicate significant association with PUs at the $5 \%$ level.

In our study, a higher proportion of patients had cervical lesions, compared with thoracic and lumbosacral injuries. Particularly in this cohort, 26\% had lesions across C1-4, with 10 subjects having complete injuries. Those with cervical lesions have an increased susceptibility to pulmonary complications due to weakness of respiratory muscles that necessitates the use of mechanical ventilation. Commonly, this mode of ventilation had been found to be associated with ventilator-acquired pneumonia where the risk increases between 1 and $3 \%$ per intubation day. ${ }^{16} \mathrm{~A}$ similar trend of increased pulmonary complications in those with cervical lesions had been previously noted. ${ }^{2}$ UTIs were the third most common complication, likely owing to the presence of neurogenic bladder after a tSCI. In this study, UTIs were significantly associated with completeness of injury $(P<0.01)$, but not with neurological level. Of importance to the discourse, at the hospital, most of the patients with complete injuries were routinely inserted an indwelling catheter. Evidence exists to support the benefits, in terms of a lower prevalence of UTIs, of using less invasive methods (intermittent catheterisation) for neurogenic bladder, compared with the use of indwelling catheters. One reason for this is that the latter method is known for inoculating organisms into the bladder. ${ }^{17,18} \mathrm{~A}$ study is required to investigate the reasons for the use of indwelling catheters at the unit and also to determine the cost benefits that are associated with less invasive methods.

On the basis of univariate logistic regression models, significant risk factors for PUs included gun-shot injury, motor completeness, presence of vertebral injuries, pulmonary complications, UTI and level of consciousness. A significant protective effect was found for those who underwent spinal surgery. The Waterlow Risk Assessment Scale currently in use, but partially utilised in some departments managing acute survivors of $\mathrm{tSCI}$, does not include 'risk-factor items' concerning gun-shot injury, completeness of injury, UTI and level of consciousness. ${ }^{19}$ It is recommended that the risk factors found in this population-based cohort study are considered as additions to the Waterlow scale, or that a more SCI-specific risk assessment scale is used owing to the persisting high prevalence of PUs during the specialised acute care phase. ${ }^{20}$ The fitted multivariable logistic regression model retained motor completeness and vertebral injury as significant and independent risk factors. We used motor incompleteness as a proxy for mobility function, a well-established factor for 
PUs. ${ }^{11}$ The consensus regarding vertebral injuries as risk factor for PUs remains inconclusive; however, we found high level evidence suggesting this variable as risk factor according to Gélis and colleagues criteria. ${ }^{8}$ We believe that this factor is highly contextual given the current management of $\mathrm{tSCI}$ in the acute phase. We speculate that the delay in spinal surgery (median 7 days) could predispose a survivor to prolonged periods of immobility. Prior to stabilisation surgery, patients are recommended not to turn/move to prevent further decline in neurological status. As the current risk assessment scale does not explicitly assess these factors, patients with these risk profiles could be misclassified for the regular turning program.

Although not exhaustive, this study investigated a wider range of selected secondary medical complications in patients with traumatic spinal cord lesions in the (specialised) acute phase of injury and care in South Africa. The strength of this study was the populationbased approach; thus, enhancing the generalisability of findings that could assist with the appropriate allocation of resources and estimation of health costs associated with tSCI within the region. In contrast to the potential drawback of retrospective studies and limitation of studying exposures, this study was prospective in nature, which ensured the inclusion of relevant covariates for studying risk factors for PUs.

The study presents with some noteworthy limitations. This was a public health study conducted in the Western Cape that included patients with tSCI utilising government-funded healthcare services. Thus, a knowledge gap persists regarding the prevalence of secondary medical complications in survivors of tSCI with private healthcare insurance. Concerning the secondary medical complications, we were limited to include the complications routinely assessed at the hospital, therefore some other critical complications, such as hyponatremia, labile blood pressure, paralytic ileus and bowel dysfunctions, were not reported. In addition, we were not able to systematically evaluate mobility/functioning as a potential risk factor for PU development. Instead, we used motor complete (ASIA A $\mid$ B) and motor incomplete (ASIA C $\mid D$ ) lesions as a proxy for functional mobility.

In conclusion, PUs and pulmonary complications were the most common secondary medical complications following acute tSCI. Now with the identification of risk factors for PUs, it is important to prioritise and implement preventive strategies for those with motor complete lesions and those with vertebral injuries.

\section{DATA ARCHIVING}

There were no data to deposit.

\section{CONFLICT OF INTEREST}

The authors declare no conflict of interest.

\section{ACKNOWLEDGEMENTS}

We would like to thank all subjects for their participation in this study. Further, we would like to thank Dr Stander and Dr Sothman for carrying out the evaluations.

1 Capoor J, Stein AB. Aging with spinal cord injury. Phys Med Rehabil Clin N Am 2005; 16: $129-161$.

2 van Weert KC, Schouten EJ, Hofstede J, van de Meent H, Holtslag HR, van den Berg-Emons RJ. Acute phase complications following traumatic spinal cord injury in Dutch level 1 trauma centres. J Rehabil Med 2014; 46: 882-885.

3 Sweet SN, Noreau L, Leblond J, Dumont FS. Understanding quality of life in adults with spinal cord injury via SCl-related needs and secondary complications. Top Spinal Cord Inj Rehabil 2014; 20: 321-328.

4 Consortium SCM. Early acute management in adults with spinal cord injury: a clinical practice guideline for health-care professionals. J Spinal Cord Med 2008; 31 403-479.

5 Joseph C, Delcarme A, Vlok I, Wahman K, Phillips J, Nilsson Wikmar L. Incidence and aetiology of traumatic spinal cord injury in Cape Town, South Africa: a prospective, population-based study. Spinal Cord 2015; 53: 692-696.

6 Frielingsdorf K, Dunn RN. Cervical spine injury outcome-a review of 101 cases treated in a tertiary referral unit. S Afr Med J 2007; 97: 203-207.

7 Dunn RN, Stander J. Pressure sores in spinal cord injury: Active intervention saves costs. South African Journal of Critical Care 2008; 24: 8-12.

8 Gélis A, Dupeyron A, Legros P, Benaïm C, Pelissier J, Fattal C. Pressure ulcer risk factors in persons with SCl: part I: acute and rehabilitation stages. Spinal Cord 2009; 47: 99-107.

9 Byrne DW, Salzberg CA. Major risk factors for pressure ulcers in the spinal cord disabled: a literature review. Spinal Cord 1996; 34: 255-263.

10 Zakrasek EC, Creasy G, Crew JD. Pressure ulcers in people with spinal cord injury in developing nations. Spinal Cord 2014; 53: 7-13.

11 Verschueren JH, Post MW, de Groot S, van der Woude LH, van Asbeck FW, Rol M. Occurrence and predictors of pressure ulcers during primary in-patient spinal cord injury rehabilitation. Spinal Cord 2011; 49: 106-112.

12 Chen D, Apple DF Jr, Hudson LM, Bode R. Medical complications during acute rehabilitation following spinal cord injury-current experience of the Model Systems. Arch Phys Med Rehabil 1999; 80: 1397-1401.

13 DeVivo MJ, Biering-Sorensen F, Charlifue S, Noonan V, Post M, Stripling T et al. International Spinal Cord Injury Core Data Set. Spinal Cord 2006; 44: 535-540.

14 Waring WP III, Biering-Sorensen F, Burns S, Donovan W, Graves D, Jha A et al. 2009. review and revisions of the international standards for the neurological classification of spinal cord injury. J Spinal Cord Med 2010; 33: 346-352.

15 Krause JS, Broderick L. Patterns of recurrent pressure ulcers after spinal cord injury: Identification of risk and protective factors 5 or more years after onset. Arch Phys Med Rehabil 2004; 85: 1257-1264.

16 Ball PA. Critical care of spinal cord injury. Spine 2001; 26: S27-S30.

17 De Ruz AE, Leoni EG, Cabrera RH. Epidemiology and risk factors for urinary tract infection in patients with spinal cord injury. J Urol 2000; 164: 1285-1289.

18 Trautner BW, Darouiche RO. Prevention of urinary tract infection in persons with spinal cord injury. J Spinal Cord Med 2002; 25: 277-283.

19 Waterlow J. Pressure sores: risk assessment card. Nurs Times 1985; 81: 49-55.

20 Salzberg CA, Byrne DW. A new pressure ulcer risk assessment scale for individuals with spinal cord injury. Am J Phys Med Rehab 1996; 75: 96-104.

Supplementary Information accompanies this paper on the Spinal Cord website (http://www.nature.com/sc) 